www.jmscr.igmpublication.org

Impact Factor 5.84

Index Copernicus Value: 83.27

ISSN (e)-2347-176x ISSN (p) 2455-0450

crossref DOI:_https://dx.doi.org/10.18535/jmscr/v5i5.83

Journal Of Medical Science And Clinical Research

\title{
A Study of Nasociliary Motility in Patients with Bilateral Bronchiectasis and in Smokers
}

\author{
Authors \\ Santhosh Kumar P.V ${ }^{1}$, Rajagopal T.P ${ }^{2}$, Lisha P.V \\ ${ }^{1}$ Associate Professor, ${ }^{2}$ Professor, ${ }^{3}$ Senior Resident \\ Dept. of Pulmonary Medicine, Institute of Chest Diseases, Medical College, Calicut \\ Email:drpvsk@rediffmail.com
}

\begin{abstract}
Diseases of ciliary motility may be congenitally acquired and lead to recurrent sinopulmonary infections and bronchiectasis. Tobacco smoking also leads to various acquired disorders of ciliary function. It is possible to determine ciliary motility using the simple bedside test of saccharin clearance by modified Anderson technique.

Aim of Study: To find out the time taken for the Saccharin placed on inferior turbinate of the nose to reach the oropharynx in normal individual patients with bilateral bronchiectasis and in smokers.

Materials and Method: The study was conducted in patients with bilateral bronchiectasis who attended the department of respiratory, Medicine, Institute of Chest Diseases Calicut Medical College, formed the subject of this study. Ciliary motility study by Saccharin clearance test. 50 healthy nonsmoking males and females were taken as control subjects for the test.

Results: 50 patients were included in the study. The age of the patients ranged from 9-60 years. Duration of illness ranged from 1 to 20 years. Pseudomonas was the most commonly isolated agent in sputum culture (12 out of 29 cultures). The normal maximum saccharine clearance time estimated in healthy non smoker males was 10.7 minutes and in healthy nonsmoker females was 9.6 minutes. Majority of smokers (66\%) showed a saccharine clearance time of more than 11 minutes. The majority of bronchiectasis patients (80\%) had saccharin clearance time between 20 - 50 minutes. The maximum mean saccharin clearance time in bronchiectasis patients was 46.5 minutes

Conclusions: Saccharin clearance in significant proportion of smokers was increased compared to normal healthy volunteers.

$-80 \%$ of bronchiectasis patients showed very high saccharine clearance time.

-Saccharin clearance test is simple, noninvasive, least expensive and reproducible bedside test to study ciliary motility.
\end{abstract}

\section{INTRODUCTION}

The mucociliary system is an important defence mechanism in protecting both upper and lower respiratory tracts. It depends on the interaction between Cilia and mucus. Ciliary motility is affected in various diseases of bronchopulmonary system leading to chronic bronchopulmonary infections, resulting in bronchiectasis.

Primary Ciliarydyskinesia is the generic term for a hetrogenous group of inherited diseases in which 
ciliary ultrastructure is defective, and as a consequence, ciliary motility is disturbed. ${ }^{1}$

Many constituents of tobacco smoke can impair mucociliary function.

It is impossible to use highly sophisticated procedures like ciliary beat frequency by photoelectric method, or by using radioactive material and gamma camera and electronmicroscopy to study the ciliary function under our present circumstances. Hence saccharin clearance test by using modified Anderson technique may be helpful to easily detect patients with abnormal or absent ciliary motility. The test is simple, noninvasive and least expensive and reproducible. It requires only proper co-operation of the patient.

Stanley P.J found that acrolein in cigarette smoke was highy ciliotoxic. ${ }^{2}$ Agius and co-workers detected the marked ciliotoxic effect of cotitine which is a metabolite of nicotine. ${ }^{3}$

Chronic irritation of the airways by tobacco smoke can lead to hyperplasia and hypertrophy of mucusglands. This can cause hyper secretion of mucus, mainly the viscid gel layer, resulting in abnormal ciliary function. In 1995 Wake M and Smallman demonstrated reduced ciliary beat frequency in adult smokers and in children who were passive smokers. ${ }^{4}$

\section{AIM OF STUDY}

To find out the time taken for the Saccharin placed on inferior turbinate of the nose to reach the oropharynx in normal individual patients with bilateral bronchiectasis and in smokers.

\section{MATERIALS AND METHOD Materials}

Subjected studied were divided into 3 groups. Group I- 50 Nonsmoking healthy subjects

Group II- 50 patients with definite history and clinical evidences of bilateral bronchiectasis Group III-50 smokers, who smoked atleast 10 beedies or cigarettes per day at least for 2 years

Methods
Each patient was told in detail about the test to be performed and his/her consent was taken. Routine haematological examination.Sputum for acid fast bacilli.Urine analysis. X-ray chest. E.C.G. C.T Scan Thorax, where done.

Ciliary motility study by Saccharin clearance test. Saccharin particles were placed on the inferior nasal turbinate $1 \mathrm{~cm}$ from its anterior end. The time taken from placement of saccharin particles to the first experience of sweet taste by the subject was recorded in minutes. The subject was positioned with head slightly forwards and instructed not to sniff, cough, eat or drink during the test.

\section{RESULTS AND ANALYSIS}

Age and Sex distribution

The sex ratio of 50 cases studied

\begin{tabular}{|c|c|c|c|}
\hline $\begin{array}{c}\text { Total No. } \\
\text { of cases }\end{array}$ & Males & Females & M:F \\
\hline 50 & 33 & 17 & $1.84: 1$ \\
\hline
\end{tabular}

50 patients with bilateral bronchiectasis who attended the department of respiratory, Medicine, Institute of Chest Diseases Calicut Medical College, formed the subject of this study.

Age and Sex distribution of 50 cases under study

\begin{tabular}{|c|c|c|c|c|c|c|c|}
\hline $\begin{array}{l}\stackrel{0}{z} \\
\dot{\sim}\end{array}$ & 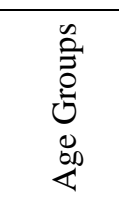 & 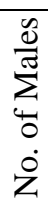 & 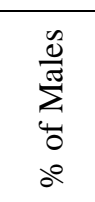 & 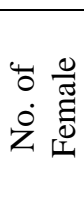 & 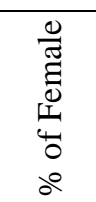 & 疍 & $\begin{array}{l}\bar{\pi} \\
0 \\
0 \\
0 \\
0 \\
0\end{array}$ \\
\hline 1 & $0-10$ & 1 & 3.03 & Nil & 0 & 1 & 2 \\
\hline 2 & $11-20$ & 8 & 24.24 & 1 & 5.88 & 9 & 18 \\
\hline 3 & $21-30$ & 12 & 36.37 & 11 & 64.71 & 23 & 46 \\
\hline 4 & $31-40$ & 8 & 24.24 & 3 & 17.65 & 11 & 22 \\
\hline 5 & $41-50$ & 3 & 9.09 & 2 & 11.76 & 5 & 10 \\
\hline 6 & $\begin{array}{c}\text { Above } \\
50\end{array}$ & 1 & 3.03 & 0 & 0 & 1 & 2 \\
\hline \multicolumn{2}{|c|}{ Total } & 33 & $100 \%$ & 17 & $\begin{array}{c}100 \\
\%\end{array}$ & 50 & $\begin{array}{c}100 \\
\%\end{array}$ \\
\hline
\end{tabular}

The age of the 50 patients ranged from 9-60. 60\% belonged to the 11-30 age group. Among the 50 cases there were 4 cases of Kartagener's syndrome (1 Male and 3 Females). The youngest patient was a 9 year old male and the eldest was a 60 year old male. 


\section{Duration of Illness}

\begin{tabular}{|c|c|c|c|c|}
\hline $\begin{array}{l}\stackrel{\circ}{z} \\
\dot{\sim}\end{array}$ & 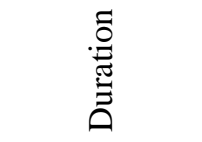 & $\frac{\tilde{d}}{\frac{\pi}{\pi}}$ & 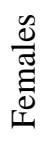 & 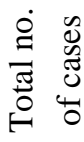 \\
\hline 1 & Below 1 year & 0 & 0 & 0 \\
\hline 2 & $1-5$ years & 3 & 0 & 3 \\
\hline 3 & $6-10$ years & 16 & 5 & 21 \\
\hline 4 & $11-20$ years & 11 & 9 & 20 \\
\hline 5 & $\begin{array}{c}\text { More than } 20 \\
\text { years }\end{array}$ & 3 & 3 & 6 \\
\hline \multicolumn{2}{|r|}{ Total } & 33 & 17 & 50 \\
\hline
\end{tabular}

The duration illness varied widely among the patients. 6 patients had more than 20 years of illness, 20 patients had $11-20$ years of illness, 21 patients had $6-10$ years of illness and 3 patients had $1-5$ years of illness.

\section{Sputum culture result}

\begin{tabular}{|c|c|c|c|c|}
\hline $\begin{array}{l}\stackrel{\circ}{z} \\
\dot{s}\end{array}$ & 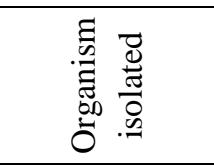 & $\frac{0}{\tilde{\pi}}$ & $\underset{\frac{0}{\tilde{E}}}{\stackrel{0}{0}}$ & 吾 \\
\hline 1 & Klebsiella & 5 & 4 & 9 \\
\hline 2 & Pseudomonas & 4 & 8 & 12 \\
\hline 3 & Normal flora & 5 & 0 & 5 \\
\hline 4 & $\begin{array}{c}\text { No organism } \\
\text { isolated }\end{array}$ & 2 & 1 & 3 \\
\hline
\end{tabular}

Sputum culture and sensitivity was done in 29 patients for pyogenic organism. Pseudomona was isolated from 12 patients and Klebsiella from 9 patients. In 5 patients the culture report came as normal flora and in 3 patients no organism was detected.

\section{Saccharin clearance time in controls}

For this purpose 25 healthy non smoking males and 25 healthy non smoking females were tested for saccharin clearance time.

Ciliary motility by Saccharin clearance in adult healthy males and females

\begin{tabular}{|c|c|c|c|}
\hline હેّ & 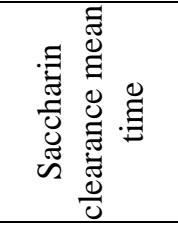 & 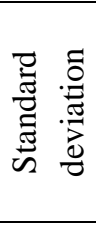 & 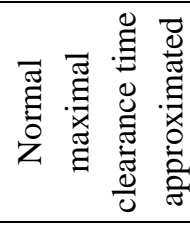 \\
\hline Males & 8.8 minutes & 1.89 & 10.7 minutes \\
\hline Females & 7.5 & 2.07 & 9.6 minutes \\
\hline
\end{tabular}

Saccharin clearance time in smokers

\begin{tabular}{|c|c|c|}
\hline Saccharin clearance time & No. of smokers & $\%$ \\
\hline Less than 11 minutes & 17 & 34 \\
\hline 11 to 15 minutes & 28 & 56 \\
\hline 16 to 20 minutes & 5 & 10 \\
\hline More than 20 minutes & 0 & 0 \\
\hline Total & 50 & 100 \\
\hline
\end{tabular}

Majority of smokers (66\%) showed abnormal mucociliary clearance as compared to the control group. (Saccharin clearance time 10.7 minutes) Saccharin clearance time patients with
bilateral bronchiectasis

\begin{tabular}{|c|c|c|c|c|c|c|c|}
\hline $\begin{array}{l}\dot{0} \\
\dot{Z} \\
\dot{n}\end{array}$ & 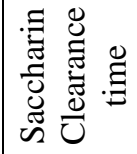 & $\frac{0}{\Sigma}$ & $\frac{d}{\frac{0}{\pi}}$ & 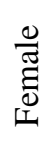 & 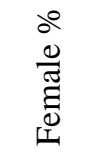 & $\stackrel{\text { 평 }}{0}$ & $\frac{0}{\sqrt{0}}$ \\
\hline 1 & $\begin{array}{l}\text { Less } \\
\text { than } \\
15 \mathrm{mts}\end{array}$ & 0 & 0 & 0 & 0 & 0 & 0 \\
\hline 2 & $15-20$ & 3 & 9.09 & 1 & 5.88 & 4 & 8 \\
\hline 3 & $21-30$ & 8 & 24.24 & 3 & 17.65 & 11 & 22 \\
\hline 4 & $31-40$ & 13 & 39.39 & 6 & 35.29 & 19 & 38 \\
\hline 5 & $41-40$ & 6 & 18.19 & 4 & 23.53 & 10 & 20 \\
\hline 6 & $51-60$ & 3 & 9.09 & 1 & 5.88 & 4 & 8 \\
\hline 7 & $\begin{array}{c}\text { More } \\
\text { than } 60\end{array}$ & 0 & 0 & 2 & 11.70 & 2 & 4 \\
\hline \multicolumn{2}{|r|}{ Total } & 33 & 100 & 17 & 100 & 50 & 100 \\
\hline
\end{tabular}

The majority of bronchiectasis patients $(80 \%)$ had saccharin clearance time between $20-50$ minutes. $12 \%$ had saccharin clearance time more than 50 minutes and $8 \%$ had $15-20$ minutes.

\section{DISCUSSION}

Saccharin clearance time is a very simple noninvasive method to study nasociliary motility. In this study this test was used in 50 cases of bilateral bronchiectasis and in chronic smokers to find out the abnormality in nasociliary clearance time and the results were compared with that of healthy controls.

Among the 50 patients taken up for study there were 33 males and 17 females. The sex ratio of male and female was 1.84:1. The male predominance has been described by other workers like Wyn, Williams etc. The majority of patients were in the $11-30$ years of age group (64\%) which is also reported by others. $94 \%$ of them had symptoms for more than 5 years. Cough 
and purulent expectoration were present in all cases. Sputum anaerobic culture was not done. Aerobic culture showed predominance of pseudomonas.

Nasociliary motility study using saccharin clearance test was done in 25 healthy nonsmoking males and females. The mean maximum saccharin clearance time for male was 10.7 minutes and that of females was 9.6 minutes. There was slight difference in nasociliary motility between males and females. Jonathan Rutland and Peter.J Cole reported almost same results.

In the majority (92\%) of cases of bronchiectasis saccharin clearance time was above 20 minutes. 4 patients $(8 \%)$ had clearance time between $15-20$ minutes, which according to the mean clearance time obtained in our study is abnormal. There were 4 cases of Kartagener's syndrome among the 50 cases. The saccharin clearance in all these patients were above 30 minutes. The maximum mean saccharin clearance time in bronchiectasis patients was 46.5 minutes.

Saccharin clearance time in bronchiectasis in other studies compared to the present study

\begin{tabular}{|c|c|c|}
\hline S1. No & Study & $\begin{array}{c}\text { Saccharin } \\
\text { clearance time }\end{array}$ \\
\hline 1 & $\begin{array}{c}\text { Jonathan Rutland }_{\text {et al }}^{5} \\
48.2 \text { minute }\end{array}$ \\
\hline 2 & P.J Stanley et al $^{6}$ & 37.4 minute \\
\hline 3 & Present study & 46.5 minute \\
\hline
\end{tabular}

In this study maximum mean saccharin clearance of smokers was 15.1 minutes. This shows prolongation of nasal mucociliary clearance in smokers as compared to that of non-smokers (10.7 minutes). This is consistent with the study done by P.J Stanley, MC William and P.J Cole.

Saccharin clearance time in Relation to the Duration of Smoking

\begin{tabular}{|l|l|l|}
\hline Sl. No & Duration of Smoking & $\begin{array}{l}\text { Saccharin clearance } \\
\text { time }\end{array}$ \\
\hline 1 & $2-10$ years & 9.8 minutes \\
\hline 2 & $11-20$ years & 13.9 minutes \\
\hline 3 & More than 20 years & 16.2 minutes \\
\hline
\end{tabular}

Our study showed prolongation of saccharin clearance time with increase in duration of smoking.

\section{SUMMARY AND CONCLUSION}

Bronchiectasis is still a common clinical problem in this state. Male predominate in the sex ratio (1.84:1). Common symptoms were cough and purulent expectoration and the signs were coarse leathery crackles. Abnormal saccharin clearance time was found in all cases of bilateral bronchiectasis. The mean maximum saccharin clearance in bilateral bronchiectasis patients was 46.5 minutes. The duration of bronchiectsis had a telling effect on saccharin clearance time. In this study there was not much of variation from the western reports about normal clearance time in bronchectasis. Saccharin clearance was prolonged in $66 \%$ of smokers. The duration of smoking had a discernible effect on nasociliary clearance time. Saccharin clearance test is simple, noninvasive, least expensive and reproducible bedside test to study ciliary motility.

\section{REFERENCES}

1. Dombi V.H, Walt.H

2. The Journal of Medicine 126 (ii): 421-33, 1996.

3. Stanley P.J and Greenstone

4. Prolonged nasal mucociliary clearance in smokers, Thorax 1980:20:239 - 240.

5. Agius. A.M. Wake.M

6. The effects of in vitro cotitine on nasal ciliary beat frequency. Clinical Otolaryngology. 20(5) 465 - 9, 1995 October.

7. Wake $\mathrm{M}$ et al 1995

8. The effect of in vitro cotitine on nasal ciliary beat frequency. Clinical Otolaryngology - 20: $465-9,1995$.

9. Rutland J. et al (1981)

10. Nasal mucociliary clearance and ciliary beat frequencyin cystic fibrosis compared with sinusitis and bronchiectasis. Thorax:39: $654-658$.

11. Philip Stanley et al (1985).

12. Abnormal nasal mucociliary clearancein patients with rhinitis and its relationshipto concomitantchest diseases.Br. J. Dis chest 79.97 97-1985 